Research Article

\title{
A Simple Model for Vertical Dynamic Interactions among a Group of Strip Footings Rested on Homogeneous Half-Space
}

\author{
Jue Wang $\mathbb{D}^{1}$ and Ding Zhou $\mathbb{D}^{2}$ \\ ${ }^{1}$ College of Mechanical \& Electrical Engineering, Hohai University, Changzhou 213022, China \\ ${ }^{2}$ College of Civil Engineering, Nanjing Tech University, Nanjing 211816, China
}

Correspondence should be addressed to Jue Wang; wjatnjut@gmail.com

Received 10 April 2018; Revised 19 June 2018; Accepted 28 June 2018; Published 25 July 2018

Academic Editor: Roberto Nascimbene

Copyright (C) 2018 Jue Wang and Ding Zhou. This is an open access article distributed under the Creative Commons Attribution License, which permits unrestricted use, distribution, and reproduction in any medium, provided the original work is properly cited.

A simple model for vertical dynamic interactions among a group of strip footings rested on half-space is presented in this paper. An analytical method is presented to obtain the contact pressures and the impedance matrix for a group of surface strip footings. In order to conveniently solve the unknown contact pressures between the soil and footings, the soil-footing interfaces are discretized into a series of strip elements. The Green function for each element under uniform harmonic force is derived and calculated by the piecewise integration and Cauchy principal value integral. The influences of footing and soil parameters on contact pressures and vertical dynamic impedances of footing groups are discussed in detail. The SSSI effect between adjacent footings increases with the decrease of the distance ratio $S / L$. For three footings in a group, the middle footing experiences greater cross-interactional effect than the side ones. The present method has high accuracy, which is not only simple but also suitable for the high-frequency analysis.

\section{Introduction}

The soil-structure interaction (SSI) has been paid comprehensive attention over the past few decades [1-3]. The substructure method has been widely applied in SSI research due to that the footing and the half-space can be analyzed separately by using the respectively suitable methods. In the substructure method, the reaction of the soil against the footing can be described by the frequency-dependent stiffness and damping coefficients which are commonly called as dynamic impedance. Therefore, it is a key step to obtain the impedance function of the footing in the analysis of SSI.

Reissner [4] derived the first analytical solution for the vertical vibration of a circular plate subjected to a harmonic uniform force and marked the beginning of the elastic halfspace theory about SSI. Sung [5] presented three kinds of supposed contact pressure distributions (static rigidity, uniform, and parabolic) beneath the footing. The dynamic impedances for some representative cases $[6,7]$ were obtained based on these assumed distributions. However, the assumed distribution could not yield a constant surface displacement of the supporting medium beneath the rigid footing as demanded from physical considerations; it is then necessary to find the mean value for the footing displacement through various averaging techniques. On the contrary, the footing impedances were analyzed more rigorously and treated as a mixed boundary-value problem. Luco and Westmann [8] presented the impedance for a massless rigid strip footing by letting the Cauchy singular dual integral equations reduce to the second kind of Fredholm integral equations. Ma et al. [9] transformed the dual integral equations into a set of linear equations using an infinite series of orthogonal Jacobi polynomials for the rocking impedance of the rigid strip footing. As the contact stresses cannot be expressed by the elementary functions, 
there are certain mathematical limitations to solve the mixed boundary-value problem. Therefore, some semianalytical approaches were presented to obtain the impedance more conveniently. Jiang and Song [10] investigated the impedance of a massless rigid strip footing by the thin layered method [11], that is, the analytical solution in the horizontal direction and the finite element discretization in the vertical direction. Lin et al. [12] studied the similar problem based on the precise integration method [13].

In the aforementioned literature, dynamic interaction between single footing and elastic half-space was considered. However, the construction of the metros and highspeed trains is becoming prevalent with the acceleration of urbanization. In such a situation, the footings associate together through soil ground. This results in the structuresoil-structure interaction (SSSI) under the externally vertical exciting loads $[14,15]$. Taking the advantage in the SSI model proposed by Parmelee [16], Warburton et al. [17] derived governing equations for the response of two geometrically identical cylindrical bodies attached to the surface of an elastic half-space, which initiates the SSSI study. Liou [18] presented an analytical solution for the dynamic stiffness matrix of adjacent surface rigid footings, based on the assumed contact stress distribution which linearly varies in the radius direction in the cylindrical coordinate system. Currently, analyses of dynamic interactions between multiple footings are mainly through numerical methods [19-22] such as the finite element method and the boundary element method due to the rapid progress in computer technique. However, these methods are far too time-consuming and complicated for actual engineering and designers. The analytical method for the impedance matrix of footing group based on the elastic half-space theory is still very rare, while it is efficient and has great significance for solving the seismic response of structure groups and assessing structure safety.

In this paper, the Green function of uniform harmonic vertical force is derived and numerically calculated by the piecewise integrations and the Cauchy principal value integral. Contact pressures and the impedance matrix of multiple strip footings considering the SSSI effect are obtained by combining the Green function with the element discretization technique. In contrast with the mixed boundary-value method, the present method avoids the directly solving of contact pressures which cannot be expressed by the elementary functions. The validity and wide applicability of the present method has been verified by the comparative studies. The SSSI effect on the contact pressures and impedances for a group of surface strip footings are illustrated by the parametric studies.

\section{General Formulation of SSSI Problem}

For the strip footings such as track footings, dams, or building footings with high ratio of length to width, it is reasonable to consider the problem as a plane strain case with a coordinate system $(x-z)$ where the $z$-axis is normal to the space surface. Consider a group of strip footings with different width $L_{m}(m=1, \ldots, M)$ and different separation distance $S_{m}$, as shown in Figure 1. $M$ footings rest on a linear elastic half-space, and the $m$ th footing is excited by the vertical harmonic line excitations $T_{m} \exp (i \omega t)(m=1, \ldots, M)$.

The SSSI effect of the system consisting of the $M$ footings can be conveniently expressed by

$$
\left\{\begin{array}{c}
T_{1} \\
\vdots \\
T_{m} \\
\vdots \\
T_{M}
\end{array}\right\}=\left[\begin{array}{ccccc}
\mathfrak{R}_{11} & \cdots & \mathfrak{R}_{1 n} & \cdots & \mathfrak{R}_{1 M} \\
\vdots & \ddots & \vdots & \ddots & \vdots \\
\mathfrak{R}_{m 1} & \cdots & \mathfrak{R}_{m n} & \cdots & \mathfrak{R}_{m M} \\
\vdots & \ddots & \vdots & \ddots & \vdots \\
\mathfrak{R}_{M 1} & \cdots & \mathfrak{R}_{M n} & \cdots & \mathfrak{R}_{M M}
\end{array}\right]\left\{\begin{array}{c}
H_{1} \\
\vdots \\
H_{m} \\
\vdots \\
H_{M}
\end{array}\right\},
$$

where $H_{m}$ represents the vertical displacement of the $m$ th footing. The impedance $\mathfrak{R}_{m n}$ in matrix [ $\left.\mathfrak{R}\right]$ is a complex number in the matrix, which describes the coupling interaction effect between the $m$ th footing and the $n$th footing. $\mathfrak{R}_{m n}=K_{m n}+i C_{m n}$, in which $i=\sqrt{-1}$. Here, the real part $K_{m n}$ acts as a spring which expresses the restraint from soil medium on the footing, whereas the imaginary part $C_{m n}$ acts as a dashpot which expresses the energy dissipation from the soil medium. Based on the above formulations, an equivalent simplified model as shown in Figure 2 visually describes the dynamic interaction among strip footings in a group through the soil.

A compact form of (1) can be written as

$$
\widehat{\mathbf{T}}=[\mathfrak{R}] \widehat{\mathbf{H}} .
$$

The impedance matrix [ $\Re$ ] should be determined with regard to the contact condition at the footing-soil interfaces. For the simplification in analysis, the interface between the supporting medium and each footing is divided into a number of surface strip elements. The coordinate information for each element is shown in Table 1. The elements beneath the $m$ th footing $(m=1, \ldots, M)$ are numbered in succession from 1 to $R_{m}$, starting from the left to the right. The width of the element is denoted by $\Delta_{m}=L_{m} / R_{m}$. It is assumed that the $r$ th element $\left(r=1, \ldots, R_{m}\right)$ of the $m$ th footing is subjected to the uniform pressure $q_{m}^{r}$, as shown in Figure 3 .

\section{Green Function for Elastic Half-Space}

Based on the Cartesian coordinate system $(x-z)$ with $z=0$ at the free surface, the wave equations in an elastic halfspace composed of homogeneous and isotropic solid are given by

$$
\begin{gathered}
\rho \frac{\partial^{2} u(x, z, t)}{\partial t^{2}}=(\lambda+G) \frac{\partial \bar{\varepsilon}}{\partial x}+G \nabla^{2} u(x, z, t), \\
\rho \frac{\partial^{2} w(x, z, t)}{\partial t^{2}}=(\lambda+G) \frac{\partial \bar{\varepsilon}}{\partial z}+G \nabla^{2} w(x, z, t),
\end{gathered}
$$

where $\rho$ is the density of the elastic soil, $G$ and $\lambda$ are the elastic Lamé constants, and $u$ and $w$ are the displacement components of the soil in $x$ and $z$ directions. The steady-state 


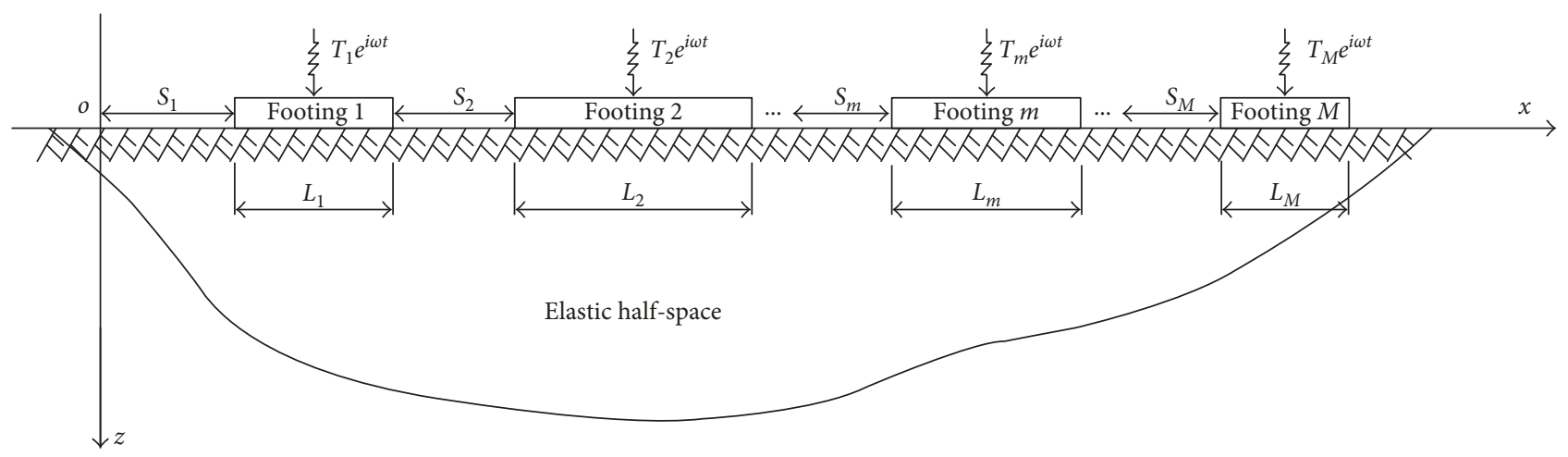

FIGURE 1: Strip footing group rested on an elastic half-space subjected to vertical harmonic excitations.

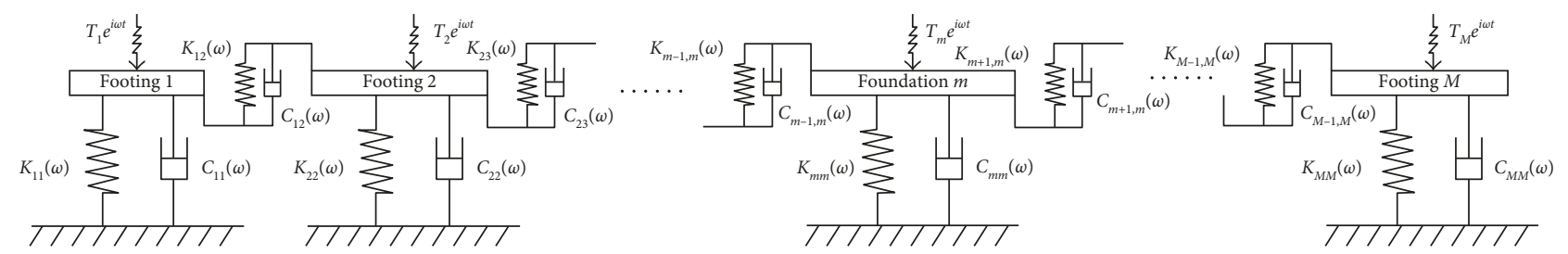

FIGURE 2: Equivalent model in frequency domain for dynamic interaction of footing group with frequency-dependent springs and dampers.

TABLE 1: Coordinate information of each element.

\begin{tabular}{|c|c|c|c|}
\hline Coordinates & $\begin{array}{l}\text { The } r \text { th element in } \\
\text { footing } 1\left(r=1, \ldots, R_{1}\right)\end{array}$ & $\begin{array}{l}\text { The } r \text { th element in } \\
\text { footing } m\left(r=1, \ldots, R_{m}\right)\end{array}$ & $\begin{array}{l}\text { The } r \text { th element in } \\
\text { footing } M\left(r=1, \ldots, R_{M}\right)\end{array}$ \\
\hline $\begin{array}{l}\text { Central coordinate } \\
\text { of each element }\end{array}$ & $S_{1}+\left((2 r-1) L_{1} / 2 R_{1}\right)$ & $\left((2 r-1) L_{m} / 2 R_{m}\right)+\sum_{l=1}^{m}\left(S_{l}+L_{l-1}\right)$ & $(2 r-1) L_{M}+\sum_{l=1}^{M}\left(S_{l}+L_{l-1}\right) / 2 R_{M}$ \\
\hline $\begin{array}{l}\text { Interval of each } \\
\text { element }\end{array}$ & $\begin{array}{c}{\left[S_{1}+\left((r-1) L_{1} / R_{1}\right)\right.} \\
\left.\quad S_{1}+\left(r L_{1} / R_{1}\right)\right]\end{array}$ & $\begin{array}{c}\left((r-1) L_{m} / N_{m}\right)+\sum_{l=1}^{m}\left(S_{l}+L_{l-1}\right) \\
\left(r L_{m} / N_{m}\right) \sum_{l=1}^{m}\left(S_{l}+L_{l-1}\right)\end{array}$ & $\begin{array}{c}\left((r-1) L_{M} / N_{M}\right)+\sum_{l=1}^{M}\left(S_{l}+L_{l-1}\right), \\
\left(r L_{M} / N_{M}\right) \sum_{l=1}^{M}\left(S_{l}+L_{l-1}\right)\end{array}$ \\
\hline
\end{tabular}

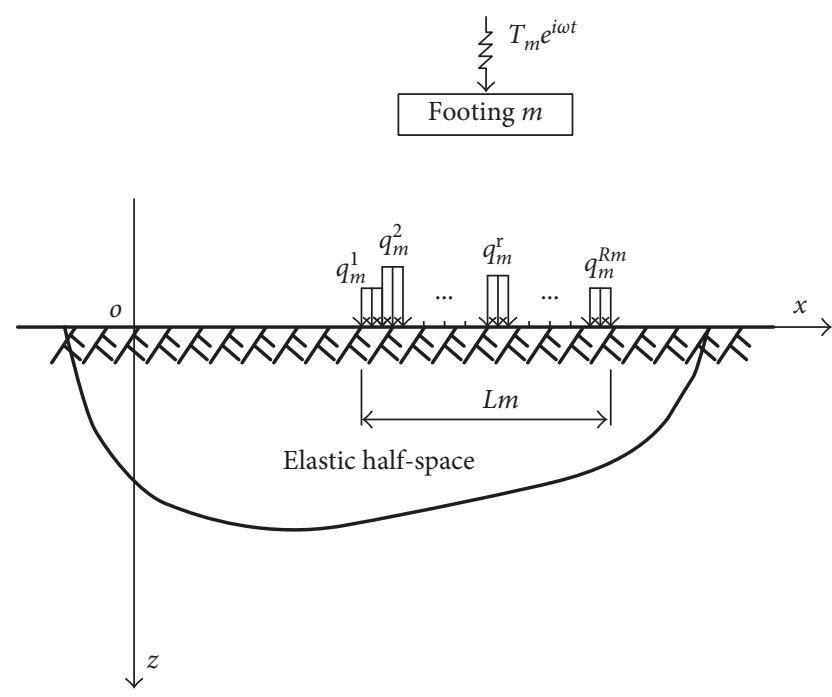

FIGURE 3: Calculation model of each strip footing in the group.

vertical dynamic of the soil satisfies $u=U e^{i \omega t}$ and $w=W e^{i \omega t}$. The term $\exp (i \omega t)$ is hereafter omitted from all displacements and forces for brevity. $\bar{\varepsilon}=(\partial u / \partial x)+(\partial w / \partial z)$ and $\nabla^{2}=\left(\left(\partial^{2} / \partial x^{2}\right)+\left(\partial^{2} / \partial z^{2}\right)\right)$ denote the volumetric strain and the Laplacian operator, respectively.

Introducing two potential functions $\Phi$ and $\Psi$, the displacement functions $U$ and $W$ are assumed to be satisfied by

$$
\begin{aligned}
& U=\frac{\partial \Phi}{\partial x}+\frac{\partial \Psi}{\partial z}, \\
& W=\frac{\partial \Phi}{\partial z}-\frac{\partial \Psi}{\partial x} .
\end{aligned}
$$

Substituting (4) in (3), the wave equations can be transformed into two Helmholtz equations:

$$
\begin{aligned}
& \left(\nabla^{2}+h^{2}\right) \Phi=0, \\
& \left(\nabla^{2}+k^{2}\right) \Psi=0,
\end{aligned}
$$

where $h=\omega / V_{p}, k=\omega / V_{s}, V_{\mathrm{p}}=\sqrt{(\lambda+2 G) / \rho}$ is the dilatational wave $\left(P\right.$ wave) velocity, and $V_{s}=\sqrt{G / \rho}$ is the shear wave ( $S$ wave) velocity.

The general solutions of (5) can be obtained by using the separation of variables method. Thereafter, making use of (4), the general solutions of displacements $U$ and $W$ in a half-space can be expressed as 


$$
U(x, z)=\int_{-\infty}^{\infty}[i \xi A \exp (-\alpha z)-\beta B \exp (-\beta z)] \exp (i \xi x) d \xi,
$$

$W(x, z)=\int_{-\infty}^{\infty}[-\alpha A \exp (-\alpha z)-i \xi B \exp (-\beta z)] \exp (i \xi x) d \xi$,

where $A$ and $B$ are the integral coefficients dependent on the boundary conditions of the soil surface, $\alpha=\sqrt{\xi^{2}-h^{2}}$ and $\beta=\sqrt{\xi^{2}-k^{2}}$.

Based on the relationships between stresses and displacements for plane problem in elasticity, $\sigma_{z z}=$ $(2 G \partial W / \partial z)+\lambda \bar{\varepsilon}$ and $\tau_{z x}=G((\partial U / \partial z)+(\partial W / \partial x))$, the stress amplitudes at an arbitrary point in half-space can be derived from (6) and (7) as follows:

$$
\begin{aligned}
\sigma_{z z}(x, z)= & G \int_{-\infty}^{\infty}\left\{\left(2 \xi^{2}-k^{2}\right) A \exp (-\alpha z)\right. \\
& +2 i \xi \beta B \exp (-\beta z)\} \exp (i \xi x) d \xi, \\
\tau_{x z}(x, z)= & G \int_{-\infty}^{\infty}\{-2 i \xi \alpha A \exp (-\alpha z) \\
& \left.+\left(2 \xi^{2}-k^{2}\right) B \exp (-\beta z)\right\} \exp (i \xi x) d \xi .
\end{aligned}
$$

Without loss of generality, we consider the vertical uniform pressure $q_{m}^{r}$ applied at a strip element, as shown in Figure 4 . The boundary conditions at the ground surface $z=0$ have

$$
\begin{aligned}
\sigma_{z z}(x, 0) & = \begin{cases}-q_{m}^{r}, & a \leq x \leq b, \\
0, & \text { others, }\end{cases} \\
\tau_{x z}(x, 0) & =0,
\end{aligned}
$$

where $[a, b]$ is the interval of strip element beneath the strip footings with its coordinate information shown in Table 1.

Making the Fourier transformation to (10) and expressing it in an integrated form with respect to the $x$-coordinate based on its inverse relationship, one has

$$
\begin{aligned}
\sigma_{z z}(x, 0) & =\frac{-q_{m}^{r}}{2 \pi i} \int_{-\infty}^{\infty} \frac{1}{\xi}\{\exp [i \xi(x-a)]-\exp [i \xi(x-b)]\} d \xi \\
\tau_{x z}(x, 0) & =\int_{-\infty}^{\infty} 0 d \xi
\end{aligned}
$$

Comparing (11) with (8) and (9), the coefficients $A$ and $B$ can be uniquely determined by

$$
\begin{aligned}
& A=\frac{i q_{m}^{r}\left(2 \xi^{2}-k^{2}\right)[\exp (-i \xi a)-\exp (-i \xi b)]}{2 \pi G F(\xi) \xi}, \\
& B=\frac{-q_{m}^{r} \alpha[\exp (-i \xi a)-\exp (-i \xi b)]}{\pi G F(\xi)} .
\end{aligned}
$$

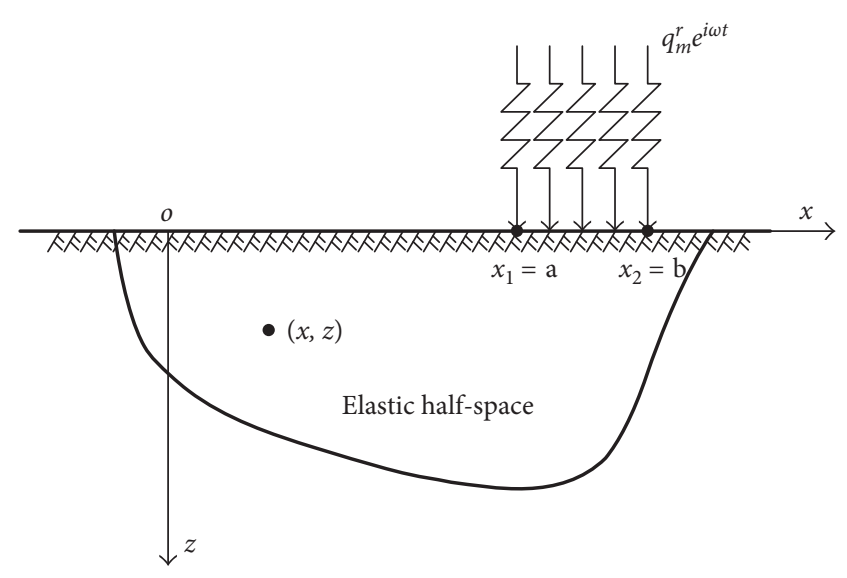

FIgURE 4: The half-space acted by a vertical harmonic uniform excitation.

Substituting the above two coefficients back in (6) and (7), the vertical displacement field $w_{m}^{r}(x, z)$ caused by the half-space caused by the uniform pressure can be obtained:

$$
\begin{aligned}
W_{m}^{r}(x, z)= & \frac{i q_{m}^{r}}{2 \pi G} \int_{-\infty}^{\infty} \frac{-\alpha\left[\left(2 \xi^{2}-k^{2}\right) \exp (-\alpha z)+2 \xi^{2} \exp (-\beta z)\right]}{F(\xi) \xi} \\
& \cdot\{\exp [i \xi(x-a)]-\exp [i \xi(x-b)]\} d \xi,
\end{aligned}
$$

in which, $F(\xi)=\left(2 \xi^{2}-k^{2}\right)^{2}-4 \xi^{2} \alpha \beta$. Letting $p=\xi / k, \vartheta=$ $V_{\mathrm{s}} / V_{\mathrm{p}}, F(\xi)$ can be transformed into $F(p)=\left(2 p^{2}-1\right)^{2}-$ $4 p^{2} \sqrt{p^{2}-\vartheta^{2}} \sqrt{p^{2}-1}$. Submitting the interval coordinates of each element into (13) and considering the symmetry of the integral, the vertical displacement field at the surface of the half-space caused by the uniform pressure $q_{m}^{r}$ of the $r$ th element beneath the $m$ th footing can be obtained as

$$
\begin{aligned}
W_{m}^{r}(x, 0)= & \frac{-q_{m}^{r}}{\pi G} \int_{0}^{\infty} \frac{\sqrt{p^{2}-\vartheta^{2}}}{k F(p) p}\left\{\operatorname { s i n } \left[p k \left(x-\frac{(r-1) L_{m}}{N_{m}}\right.\right.\right. \\
& \left.\left.-\sum_{l=1}^{m}\left(S_{l}+L_{l-1}\right)\right)\right]-\sin \left[p k \left(x-\frac{r L_{m}}{N_{m}}\right.\right. \\
& \left.\left.\left.-\sum_{l=1}^{m}\left(S_{l}+L_{l-1}\right)\right)\right]\right\} d p .
\end{aligned}
$$

\section{Impedance Matrix of a Strip Footing Group}

Following the superposition approach, the vertical displacement $W(x, 0)$ at any point of the soil surface caused by a series of strip elements beneath the footing group can be obtained from (14) as follows: 


$$
\begin{aligned}
W(x, 0)= & \sum_{m=1}^{M} \sum_{r=1}^{R_{m}} W_{m}^{r}(x, 0)=\frac{-1}{\pi G} \sum_{m=1}^{M}\left\{\sum_{r=1}^{R_{m}} q_{m}^{r} \int_{0}^{\infty} \frac{\sqrt{p^{2}-\vartheta^{2}}}{F(p) p k}\right. \\
& \cdot\left\{\sin \left[p k\left(x-\frac{(r-1) L_{m}}{R_{m}}-\sum_{l=1}^{m}\left(L_{l-1}+S_{l}\right)\right)\right]\right. \\
& \left.\left.-\sin \left[p k\left(x-\frac{r L_{m}}{R_{m}}-\sum_{l=1}^{m}\left(L_{l-1}+S_{l}\right)\right)\right]\right\} d p\right\},
\end{aligned}
$$

where $r=1, \ldots, R_{m}$ and $m=1, \ldots, M . R_{m}$ is the number of strip element beneath the $m$ th footing, and $M$ is the footing number of the group.

Substituting the central coordinate of each element into the above equation, in turn, the equilibrium equations for all strip elements can be written in a matrix form:

$$
\begin{aligned}
& {\left[\begin{array}{cccccc}
{\left[\mathbf{A}_{11}^{R_{1} R_{1}}\right]} & {\left[\mathbf{A}_{12}^{R_{1} R_{2}}\right]} & \cdots & {\left[\mathbf{A}_{1 n}^{R_{1} R_{n}}\right]} & \cdots & {\left[\mathbf{A}_{1 M}^{R_{1} R_{M}}\right]} \\
{\left[\mathbf{A}_{21}^{R_{2} R_{1}}\right]} & {\left[\mathbf{A}_{22}^{R_{2} R_{2}}\right]} & \cdots & {\left[\mathbf{A}_{2 n}^{R_{2} R_{n}}\right]} & \cdots & {\left[\mathbf{A}_{2 M}^{R_{2} R_{M}}\right]} \\
\vdots & \vdots & \ddots & \vdots & \ddots & \vdots \\
{\left[\mathbf{A}_{m 1}^{R_{m} R_{1}}\right]} & {\left[\mathbf{A}_{m 2}^{R_{m} R_{2}}\right]} & \cdots & {\left[\mathbf{A}_{m n}^{R_{m} R_{n}}\right]} & \cdots & {\left[\mathbf{A}_{m M}^{R_{m} R_{M}}\right]} \\
\vdots & \vdots & \ddots & \vdots & \ddots & \vdots \\
{\left[\mathbf{A}_{M 1}^{R_{M} R_{1}}\right]} & {\left[\mathbf{A}_{M 2}^{R_{M} R_{2}}\right]} & \cdots & {\left[\mathbf{A}_{M n}^{R_{M} R_{n}}\right]} & \cdots & {\left[\mathbf{A}_{M M}^{R_{M} R_{M}}\right.}
\end{array}\right]\left\{\begin{array}{c}
\widehat{\mathbf{q}}_{1} \\
\widehat{\mathbf{q}}_{2} \\
\vdots \\
\widehat{\mathbf{q}}_{m} \\
\vdots \\
\widehat{\mathbf{q}}_{N}
\end{array}\right\}} \\
& =\left\{\begin{array}{c}
\widehat{\mathbf{W}}_{1} \\
\widehat{\mathbf{W}}_{2} \\
\vdots \\
\widehat{\mathbf{W}}_{m} \\
\vdots \\
\widehat{\mathbf{W}}_{M}
\end{array}\right\}
\end{aligned}
$$

where

$$
\begin{aligned}
& \widehat{\mathbf{q}}_{m}=\left\{q_{m}^{1}, \ldots, q_{m}^{r}, \ldots, q_{m}^{R_{m}}\right\}^{T}, \\
& \widehat{\mathbf{W}}_{m}=\left\{W_{m}^{1}, \ldots, W_{m}^{r}, \ldots, W_{m}^{R_{m}}\right\}^{T} \text {, } \\
& {\left[\mathbf{A}_{m n}^{R_{m} R_{n}}\right]=\left[\begin{array}{ccccc}
\bar{A}_{m n}^{11} & \cdots & \bar{A}_{m n}^{1 j} & \cdots & \bar{A}_{m n}^{1 R_{m}} \\
\vdots & \ddots & \vdots & \ddots & \vdots \\
\bar{A}_{m n}^{i 1} & \cdots & \bar{A}_{m n}^{i j} & \cdots & \bar{A}_{m n}^{i R_{m}} \\
\vdots & \ddots & \vdots & \ddots & \vdots \\
\bar{A}_{m n}^{R_{n} 1} & \cdots & \bar{A}_{m n}^{R_{n} j} & \cdots & \bar{A}_{m n}^{R_{n} R_{m}}
\end{array}\right]} \\
& i=1,2, \ldots, R_{n} ; j=1,2, \ldots, R_{m} ; n, m=1,2, \ldots, M \text {. }
\end{aligned}
$$

The element $\bar{A}_{m n}^{i j}$ in matrix $\left[\mathbf{A}_{m n}^{R_{m} R_{n}}\right]$ describes the relationship between the contact pressure applied on the $j$ th element beneath the $m$ th footing and the displacement of the $i$ element beneath the $n$th footing, which is given as

$$
\bar{A}_{m n}^{i j}=\frac{-1}{\pi G} \int_{0}^{\infty} \frac{\sqrt{p^{2}-\vartheta^{2}}}{F(p) p k} J(p) d p
$$

where

$$
\begin{aligned}
J(p)= & \sin \left[p k \left(\frac{(2 i-1) L_{n}}{R_{n}}+\sum_{l=1}^{n}\left(S_{l}+L_{l-1}\right)-\left(\frac{(j-1) L_{m}}{R_{m}}\right.\right.\right. \\
& \left.\left.\left.+\sum_{l=1}^{m}\left(S_{l}+L_{l-1}\right)\right)\right)\right]-\sin \left[p k \left(\frac{(2 i-1) L_{n}}{R_{n}}\right.\right. \\
& \left.\left.+\sum_{l=1}^{n}\left(S_{l}+L_{l-1}\right)-\left(\frac{j L_{m}}{R_{m}}+\sum_{l=1}^{m}\left(S_{l}+L_{l-1}\right)\right)\right)\right]
\end{aligned}
$$

Equation (18) is a multivalue improper integral, which can be precisely calculated by the piecewise integration and the Cauchy principal value integral, which can be expressed as

$$
\bar{A}_{m n}^{i j}=\frac{1}{\pi G}\left(f_{1}+i f_{2}\right)
$$

in which,

$$
\begin{aligned}
f_{1}= & -\int_{\vartheta}^{1} \frac{\sqrt{p^{2}-\vartheta^{2}}\left(2 p^{2}-1\right)^{2}}{\left[\left(2 p^{2}-1\right)^{4}-16 p^{4}\left(p^{2}-\vartheta^{2}\right)\left(p^{2}-1\right)\right] p k} J(p) d p \\
& -\overline{\mathrm{P}} \int_{1}^{\infty} \frac{\sqrt{p^{2}-\vartheta^{2}}}{\left[\left(2 p^{2}-1\right)^{2}-4 p^{2} \sqrt{p^{2}-\vartheta^{2}} \sqrt{p^{2}-1}\right] p k} J(p) d p \\
f_{2}= & -\int_{0}^{\vartheta} \frac{\sqrt{\vartheta^{2}-p^{2}}}{\left[\left(2 p^{2}-1\right)^{2}+4 p^{2} \sqrt{\vartheta^{2}-p^{2}} \sqrt{1-p^{2}}\right] p k} J(p) d p \\
& -\int_{\vartheta}^{1} \frac{4 p^{2}\left(p^{2}-\vartheta^{2}\right) \sqrt{1-p^{2}}}{\left[\left(2 p^{2}-1\right)^{4}-16 p^{4}\left(p^{2}-\vartheta^{2}\right)\left(p^{2}-1\right)\right] p k} J(p) d p \\
& +\pi \cdot \frac{\sqrt{\varepsilon^{2}-\vartheta^{2}}}{[F(p) p]^{\prime} \mid{ }_{p=\varepsilon} k} J(\varepsilon),
\end{aligned}
$$

where $\varepsilon$ is the root of $F(p)$ and $\overline{\mathrm{P}}$ means the Cauchy principal value integral.

For brevity, (16) can be written in a compact form:

$$
[A] \widehat{\mathbf{q}}=\widehat{\mathbf{W}},
$$

in which $\widehat{\mathbf{q}}=\left\{\widehat{\mathbf{q}}_{1}^{T}, \ldots, \widehat{\mathbf{q}}_{M}^{T}\right\}$ and $\widehat{\mathbf{W}}=\left\{\widehat{\mathbf{W}}_{1}^{T}, \ldots, \widehat{\mathbf{W}}_{M}^{T}\right\}$.

In consideration of the continuous contact between the rigid footings and the soil, the displacement of the surface soil elements beneath the $m$ th rigid footing should satisfy $\widehat{\mathbf{W}}_{m}=\mathbf{H}_{m} \widehat{\mathbf{I}}_{m}$, in which $\widehat{\mathbf{I}}_{m}$ is a unit column vector of order $R_{m}$. For the system shown in Figure 1, the relationship 
between the displacements of the surface soil elements and those of the footing group should satisfy

$$
\widehat{\mathbf{W}}=[\mathbf{X}] \widehat{\mathbf{H}},
$$

in which,

$$
[\mathbf{X}]=\left[\begin{array}{cccccc}
\widehat{\mathbf{I}}_{1} & \widehat{\mathbf{0}}_{1} & \cdots & \widehat{\mathbf{0}}_{1} & \cdots & \widehat{\mathbf{0}}_{1} \\
\widehat{\mathbf{0}}_{2} & \widehat{\mathbf{I}}_{2} & \cdots & \widehat{\mathbf{0}}_{2} & \cdots & \widehat{\mathbf{0}}_{2} \\
\vdots & \vdots & \ddots & \vdots & \ddots & \vdots \\
\widehat{\mathbf{0}}_{m} & \widehat{\mathbf{0}}_{m} & \cdots & \widehat{\mathbf{I}}_{m} & \cdots & \widehat{\mathbf{0}}_{m} \\
\vdots & \vdots & \ddots & \vdots & \ddots & \vdots \\
\widehat{\mathbf{0}}_{M} & \widehat{\mathbf{0}}_{M} & \cdots & \widehat{\mathbf{0}}_{M} & \cdots & \widehat{\mathbf{I}}_{M}
\end{array}\right]
$$

where $[\mathbf{X}]$ is a matrix of dimension $\left(\sum_{m=1}^{M} R_{m}\right) \times M$ and $\widehat{\mathbf{0}}_{m}$ is a zero column vector of order $R_{m}$.

Balance of excitation force and the surface contact forces for the $m$ th footing yields $T_{m}=\left(\widehat{\mathbf{I}}_{m}\right)^{T} \widehat{\mathbf{q}}_{m} \Delta_{m}$. Therefore, one has

$$
\widehat{\mathbf{T}}=[\mathbf{Y}]^{T} \widehat{\mathbf{q}}
$$

in which,

$$
[\mathbf{Y}]=\left[\begin{array}{cccccc}
\Delta_{1} \widehat{\mathbf{I}}_{1} & \widehat{\mathbf{0}}_{1} & \cdots & \widehat{\mathbf{0}}_{1} & \cdots & \widehat{\mathbf{0}}_{1} \\
\widehat{\mathbf{0}}_{2} & \Delta_{2} \widehat{\mathbf{I}}_{2} & \cdots & \widehat{\mathbf{0}}_{2} & \cdots & \widehat{\mathbf{0}}_{2} \\
\vdots & \vdots & \ddots & \vdots & \ddots & \vdots \\
\widehat{\mathbf{0}}_{m} & \widehat{\mathbf{0}}_{m} & \cdots & \Delta_{m} \widehat{\mathbf{I}}_{m} & \cdots & \widehat{\mathbf{0}}_{m} \\
\vdots & \vdots & \ddots & \vdots & \ddots & \vdots \\
\widehat{\mathbf{0}}_{M} & \widehat{\mathbf{0}}_{M} & \cdots & \widehat{\mathbf{0}}_{M} & \cdots & \Delta_{M} \widehat{\mathbf{I}}_{M}
\end{array}\right]
$$

Submitting (22) and (23) in (25) leads to

$$
\widehat{\mathbf{T}}=[\mathbf{Y}]^{T}[\mathbf{A}]^{-1}[\mathbf{X}] \widehat{\mathbf{H}} \text {. }
$$

Finally, comparing the above equation with (1), these unknown parameters in Figure 2 can be obtained by the following impedance matrix of the footing group.

$$
[\Re]=[\mathbf{Y}]^{T}[\mathbf{A}]^{-1}[\mathbf{X}] .
$$

\section{Convergence and Comparison Studies}

Convergence and numerical stability of the proposed method are investigated with respect to the number of segmental strip elements. The vertical impedances of a single footing with different series terms are given in Table 2. It is seen from Table 2 that 100 elements for uniform pressures are enough to give results with at least three significant digits.

The vertical displacement at the soil surface under unit harmonic force is compared with that obtained by the thin layered method (TLM) [11] to verify the numerical calculation of the multivalue improper integral in the Green function (13). The parameters used are soil density $\rho=2000 \mathrm{~kg} / \mathrm{m}^{3}$, shear wave velocity $V_{\mathrm{s}}=500 \mathrm{~m} / \mathrm{s}$, Poisson's ratio $v=0.4$, the distance between the observation location and the force location $d=40 \mathrm{~m}$, and the interval width of the
TABle 2: The convergence of the vertical impedance of a single strip footing.

\begin{tabular}{lcccccc}
\hline \multirow{2}{*}{$N$} & \multicolumn{2}{c}{$a_{0}=0.25$} & \multicolumn{2}{c}{$a_{0}=1.0$} & \multicolumn{2}{c}{$a_{0}=2.0$} \\
& $K$ & $C$ & $K$ & $C$ & $K$ & $C$ \\
\hline 10 & 0.422 & 0.332 & 0.425 & 1.015 & 0.344 & 2.125 \\
20 & 0.423 & 0.336 & 0.425 & 1.033 & 0.352 & 2.165 \\
30 & 0.423 & 0.337 & 0.424 & 1.039 & 0.353 & 2.179 \\
40 & 0.423 & 0.338 & 0.424 & 1.042 & 0.354 & 2.186 \\
50 & 0.424 & 0.338 & 0.424 & 1.044 & 0.354 & 2.190 \\
60 & 0.424 & 0.339 & 0.424 & 1.045 & 0.354 & 2.193 \\
70 & $\mathbf{0 . 4 2 4}$ & $\mathbf{0 . 3 3 9}$ & 0.424 & 1.046 & 0.355 & 2.194 \\
80 & 0.424 & 0.339 & 0.424 & 1.047 & 0.355 & 2.195 \\
90 & 0.424 & 0.339 & $\mathbf{0 . 4 2 4}$ & $\mathbf{1 . 0 4 7}$ & 0.355 & 2.196 \\
100 & 0.424 & 0.339 & 0.424 & 1.047 & $\mathbf{0 . 3 5 5}$ & $\mathbf{2 . 1 9 7}$ \\
110 & 0.424 & 0.339 & 0.424 & 1.047 & 0.355 & 2.197 \\
\hline
\end{tabular}

Note. These impedance values are normalized as $K /(G \pi)$ and $C /(G \pi)$. The calculation parameters are $v=0.25, a_{0}=k L / 2$.

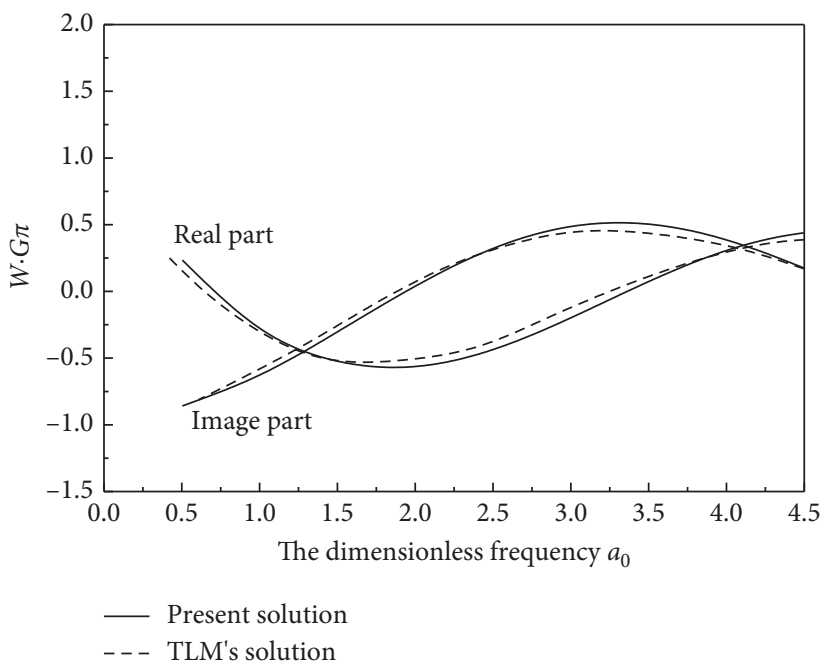

FIgURE 5: Displacement response of half-space under the harmonic vertical excitation.

uniform pressure $1 \mathrm{~m}$. The nondimensional excitation frequency is $a_{0}=k d / 2$. The displacement response of the halfspace with respect to the force-frequency is given in Figure 5. It can be seen from Figure 5 that the present solutions agree with TLM's solutions. However, there are some minor differences between the results from the two methods up to $30 \%$ in Figure 5. This is because the present model satisfies the boundary condition of a semi-infinite half-space while the TLM model used the artificial boundary. Therefore, the present solution is more accurate than that of TLM.

The flexibility of a rigid strip footing was obtained by Luco and Westmann [8] based on the mixed boundary-value approach with Fredholm integral equations. As there are considerable difficulties in solving Fredholm integral equations numerically or analytically, only a special case for Poisson's ratio $v=0.5$ was studied rigorously in Luco's solution. The cases with Poisson's ratio $v<0.5$ were approximately studied by using the dominant part of the singular integral equation to evaluate the impedances of the strip footing, which is only valid for the low frequency $a_{0} \leq 1$. 


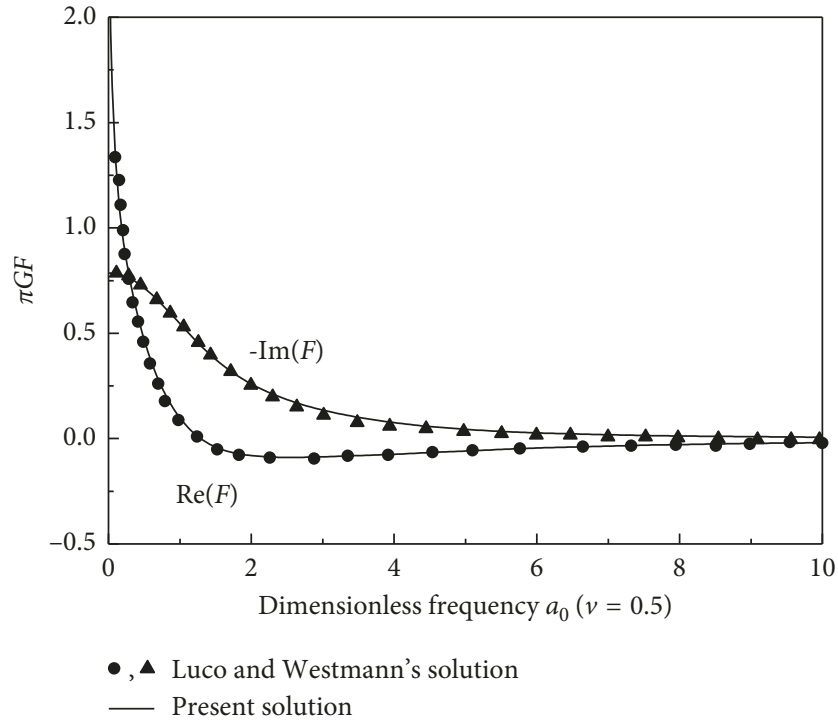

(a)

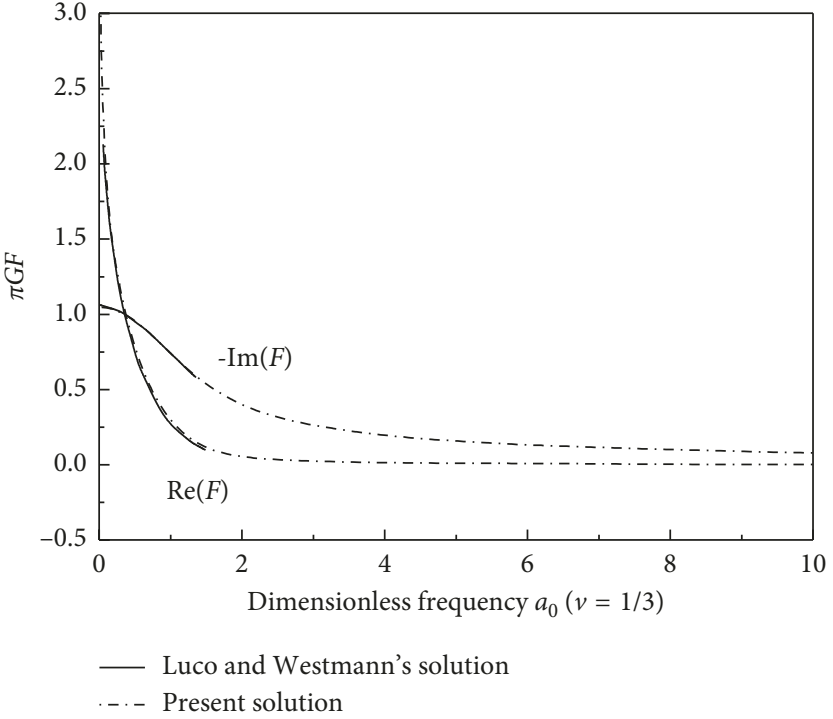

(b)

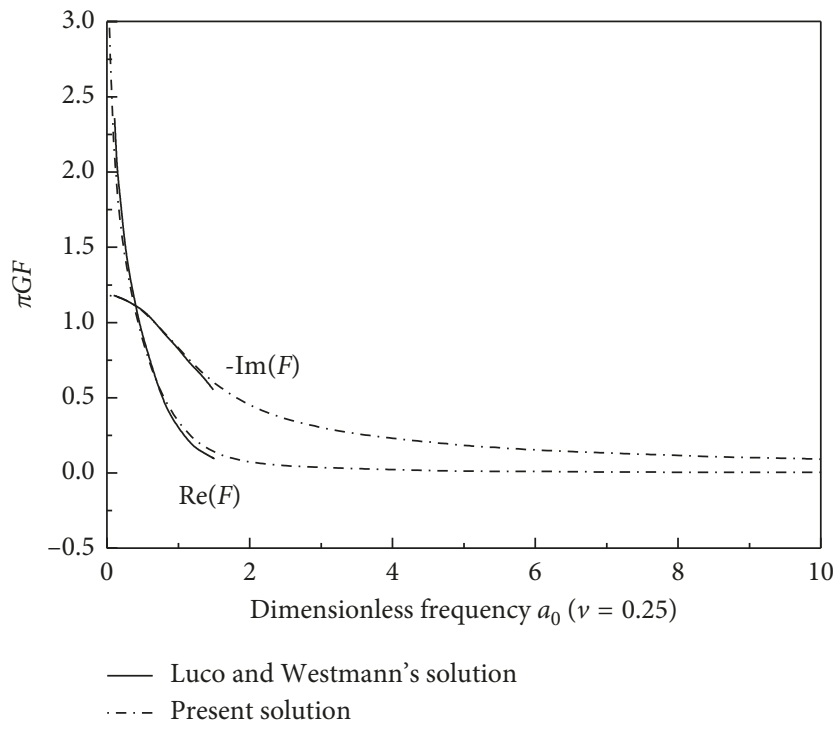

(c)

FIgURe 6: Vertical flexibility $F\left(a_{0}\right)$ of a strip footing: (a) $v=0.5$. (b) $v=1 / 3$. (c) $v=0.25$.

In order to compare with Luco's solutions, the impedance $\mathfrak{R}$ is transformed into the flexibility by $F=\mathfrak{R}^{-1}$. The flexibility of the footing with respect to dimensionless exciting frequency is plotted in Figure 6 for three different Poisson's ratios $v=0.5,1 / 3$, and 0.25 . In Figure 6 , the maximum relative errors between two solutions are less than $10 \%$. The agreement with Luco's solution approves the correctness and effectiveness of the present method. In addition, Figures 6(b) and 6(c) show that the present method covers a wider range of frequency than Luco's method.

\section{Numerical Examples and Discussions}

6.1. Vertical Dynamic Contact Pressures of Footing Group. The contact pressures of footing groups, as well as that of a single footing, under the harmonic vertical excitations with dimensionless frequencies $a_{0}=0.2$ and 3 are plotted in Figure 7 for a group of two footings and in Figure 8 for a group of three footings. Horizontal coordinate $\bar{x}$ is a local coordinate with its origin at the center of each footing. Longitudinal coordinate $\bar{q}=L q /\left(K_{\text {sig }} H\right)$ is a dimensionless contact pressure, in which $K_{\text {sig }}$ is the dynamic stiffness of a single footing and $H$ is its displacement amplitude. It also can be seen from Figure 7 that the pressure distributions of the footings in the group are different from that of a single strip footing due to the SSSI effect. Moreover, the comparison between Figures 7(a) and 7(b) indicates that the shape and magnitude of the contact pressures for both single footing and footing group change with the frequency of the excitation.

In addition, the differences between the contact pressures of footing group and those of a single footing in 


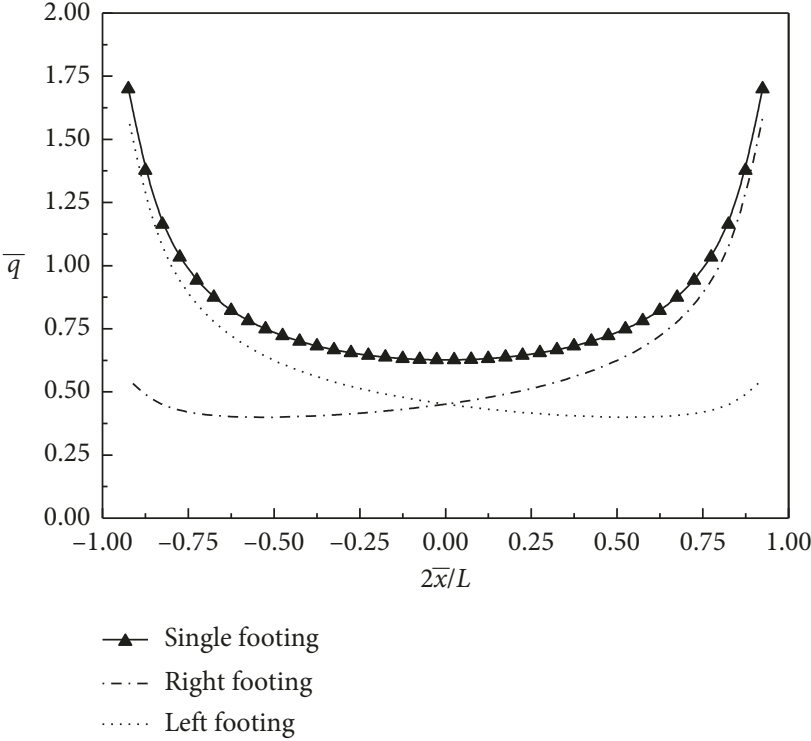

(a)

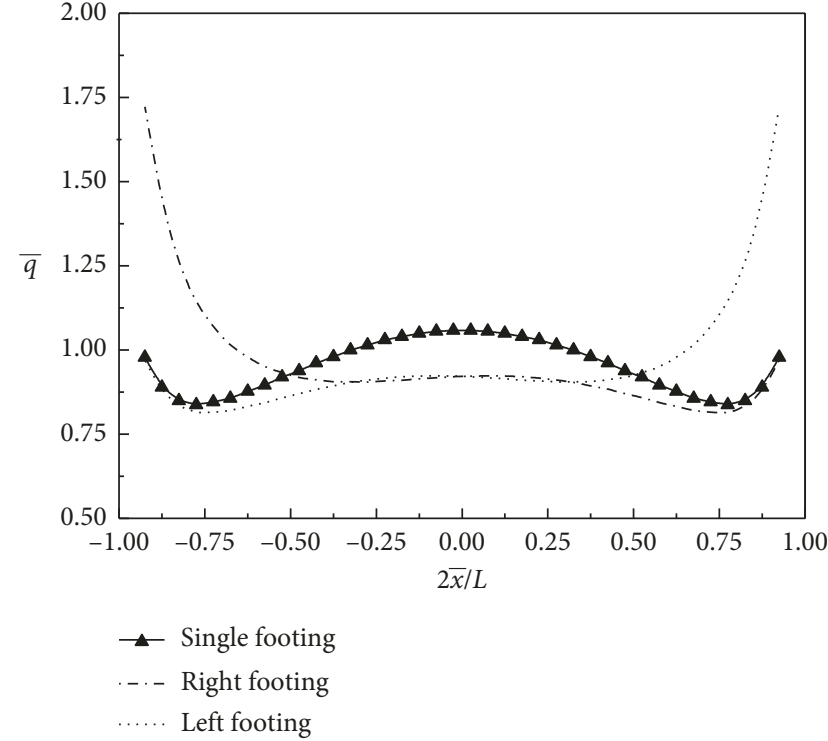

(b)

FIGURE 7: SSSI effect between two strip footings on dynamic contact pressures (footing distance ratio $S / L=0.25$; Poisson's ratio $v=1 / 3$ ). (a) $a_{0}=0.2$. (b) $a_{0}=3.0$.

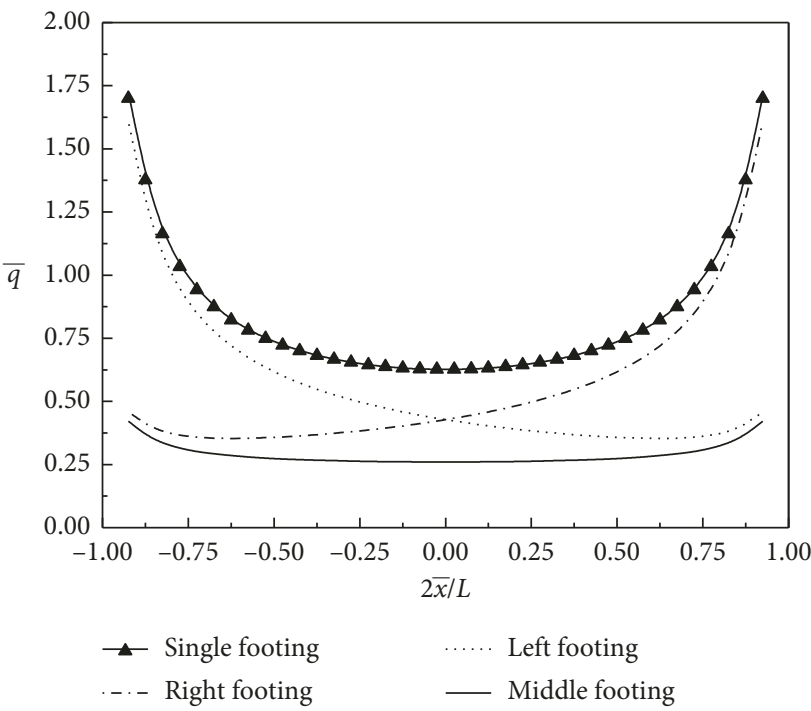

(a)

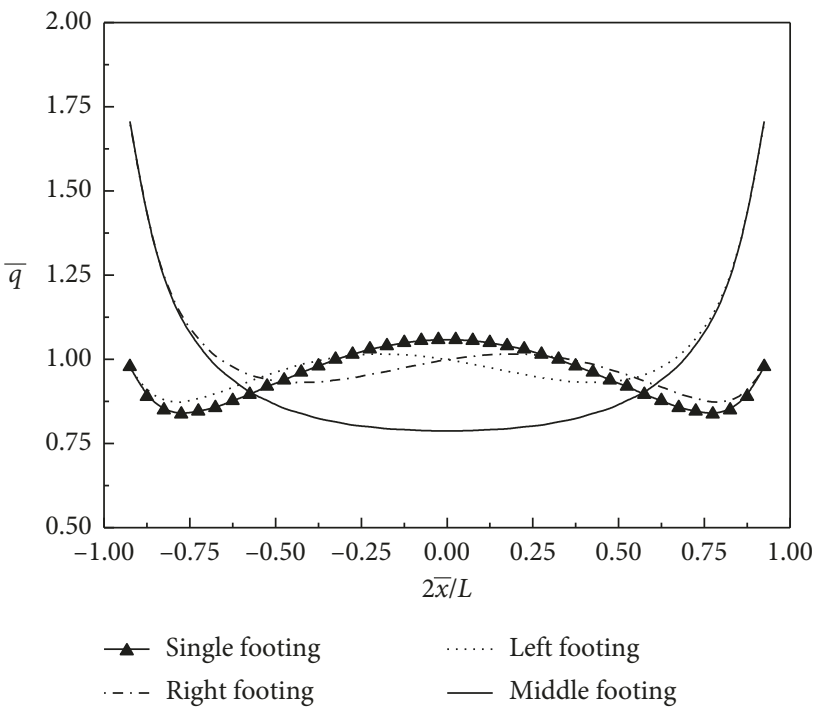

(b)

FIGURE 8: SSSI effect among three strip footings on dynamic contact pressures (footing distance ratio $S / L=0.25$; Poisson's ratio $v=1 / 3$ ). (a) $a_{0}=0.2$. (b) $a_{0}=3.0$.

Figures 7 and 8 properly indicate the significance of the SSSI effect. For two footings in Figure 7 and two side footings in Figure 8 , the pressure distribution around the outside edge is still in accord with that of a single footing, while the pressure distribution around the inside edge slopes downward because of the interference from the adjacent footing. Moreover, the middle footing in Figure 8 although presents a symmetrical distribution of pressure, its magnitude and shape are completely different from those of the single footing. Therefore, those pressure distribution assumptions for single footings would cause a considerable error in SSSI analysis.

6.2. Influence of Distance Ratio on SSSI Effect. Two adjacent strip footings with the same width $L$ and separated by a distance $S$ are used to investigate the influence of the distance ratio $S / L$ on the SSSI effect under vertical harmonic excitation. The variation of the vertical flexibility with the dimensionless frequency is plotted in Figures 9-11 for 


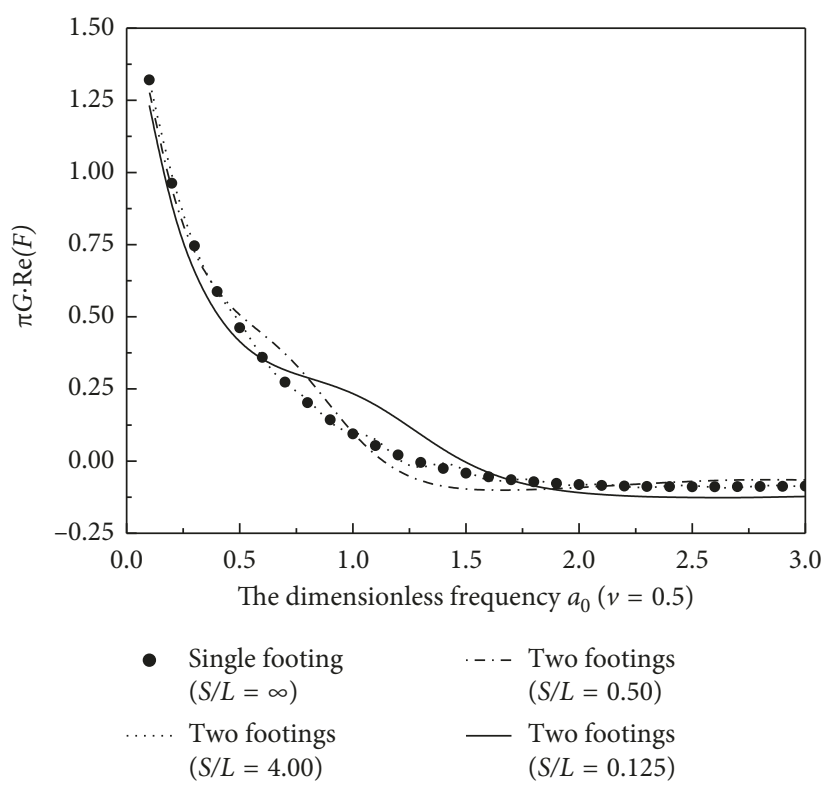

(a)

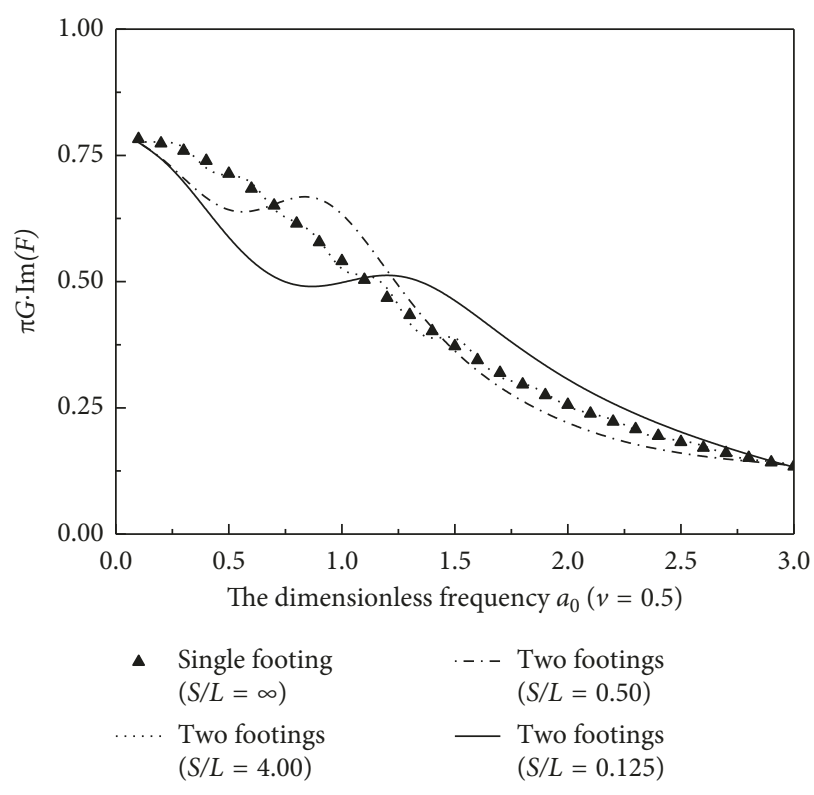

(b)

FIgURE 9: Vertical flexibility $F\left(a_{0}\right)$ in consideration of SSSI effect for $v=0.5$. (a) Real part. (b) Imaginary part.

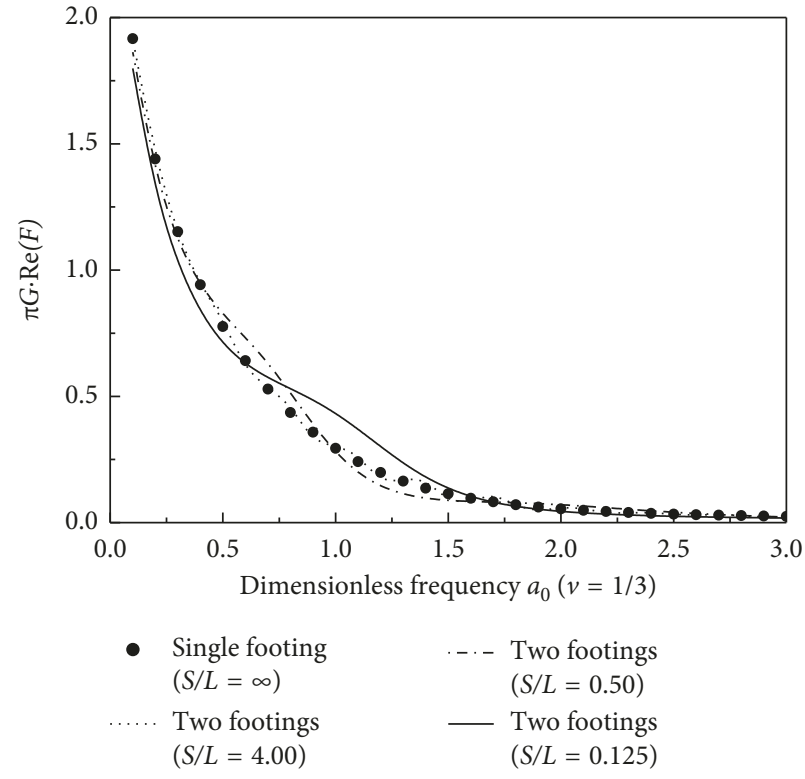

(a)

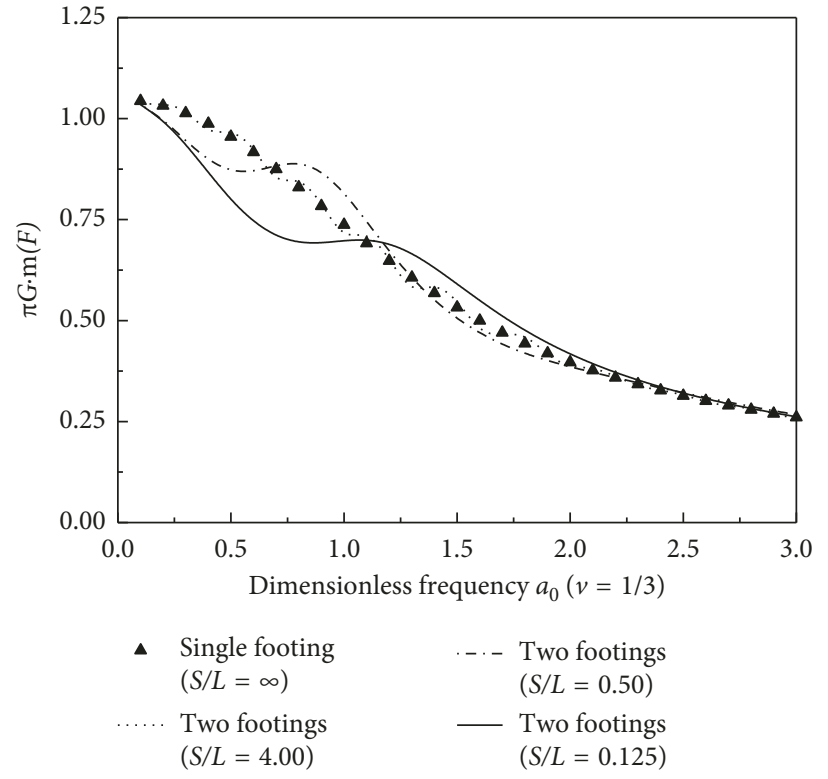

(b)

Figure 10: Vertical flexibility $F\left(a_{0}\right)$ in consideration of SSSI effect for $v=1 / 3$. (a) Real part. (b) Imaginary part.

different distance ratios $(S / L=0.125,0.5,4.0, \infty)$ and different Poisson's ratios $(v=0.25, v=1 / 3, v=0.5)$. The maximum differentia between the vertical flexibility considering the SSSI effect and that of a single footing is less than $10 \%$ in Figures $9-11$ when the distance ratio between two adjacent footings reaches $S / L=4$. However, it can be seen from Figures 9-11 that the SSSI effect between adjacent footings increases with the decrease of the distance ratio $S / L$. The vertical flexibility for the case of a small distance ratio $S / L=0.125$ shows an obvious fluctuation around the solution of an isolated footing which is induced by the SSSI effect. In addition, the comparison among Figures 9-11 shows that Poisson's ratio of the soil produces little influence on the effective distance of the SSSI effect.

\subsection{Dynamic Interaction between Multiple Strip Footings.} This example shows the matrix impedance for a group of three footings in the case of a distance ratio $S / L=0.5$ and Poisson's ratio $v=0.4$. The vertical impedances $K_{i i}$ and 


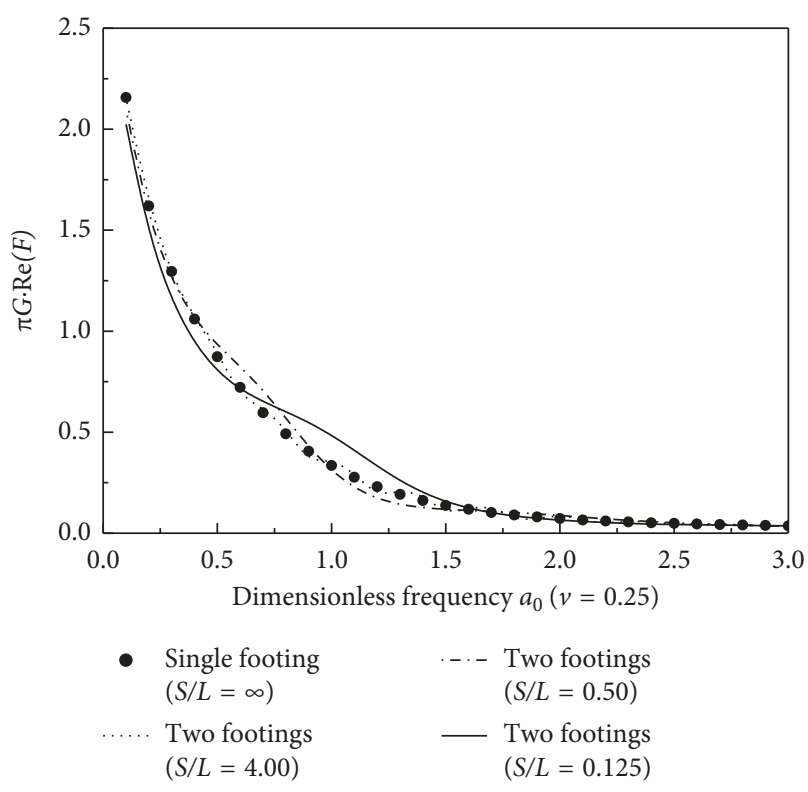

(a)

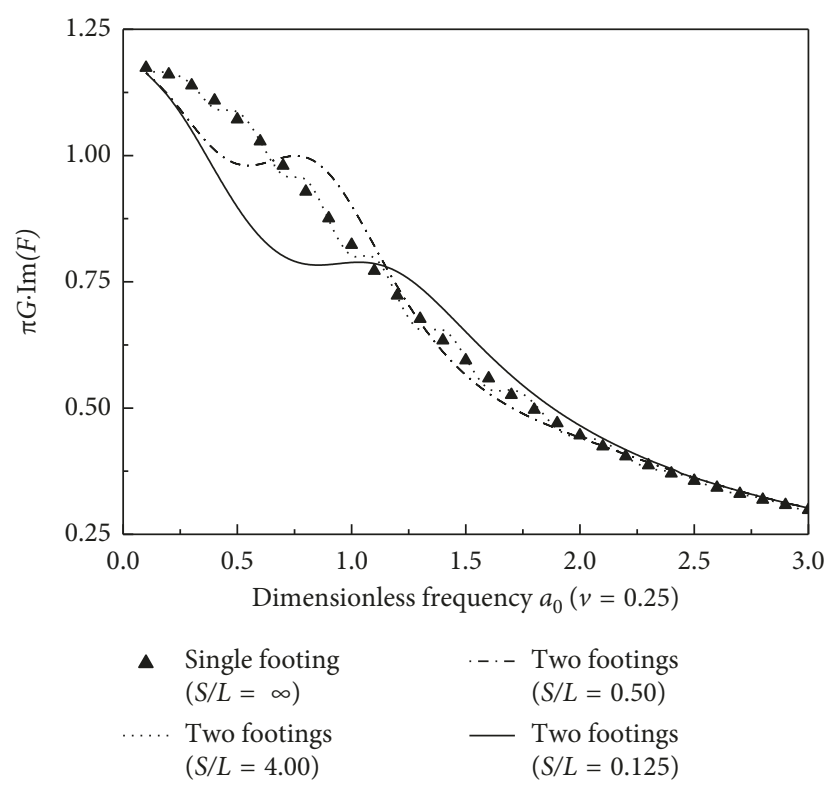

(b)

FIgURE 11: Vertical flexibility $F\left(a_{0}\right)$ in consideration of SSSI effect for $v=0.25$. (a) Real part. (b) Imaginary part.

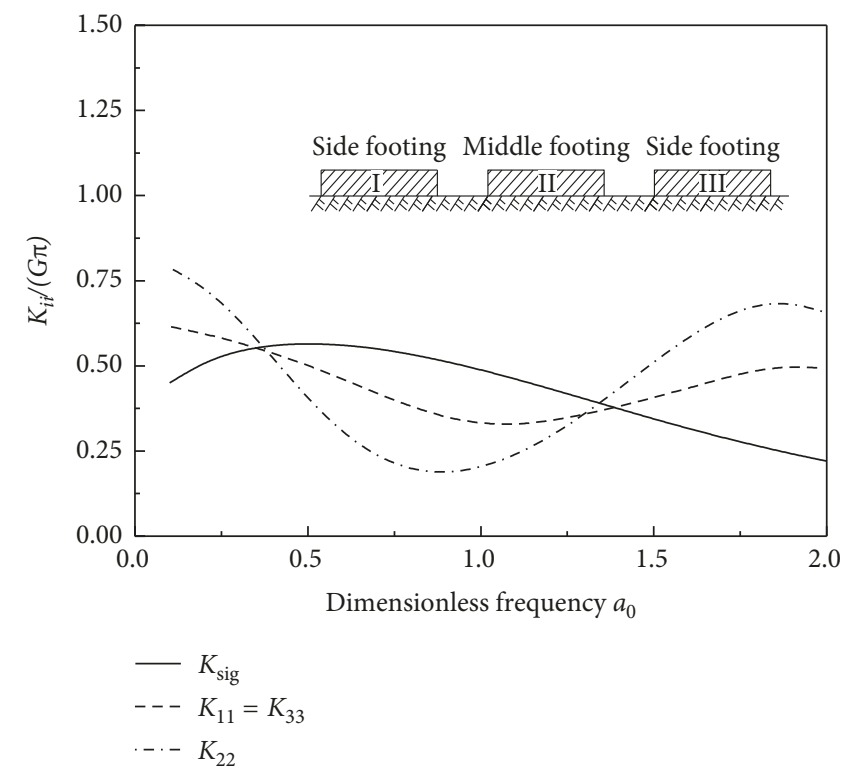

(a)

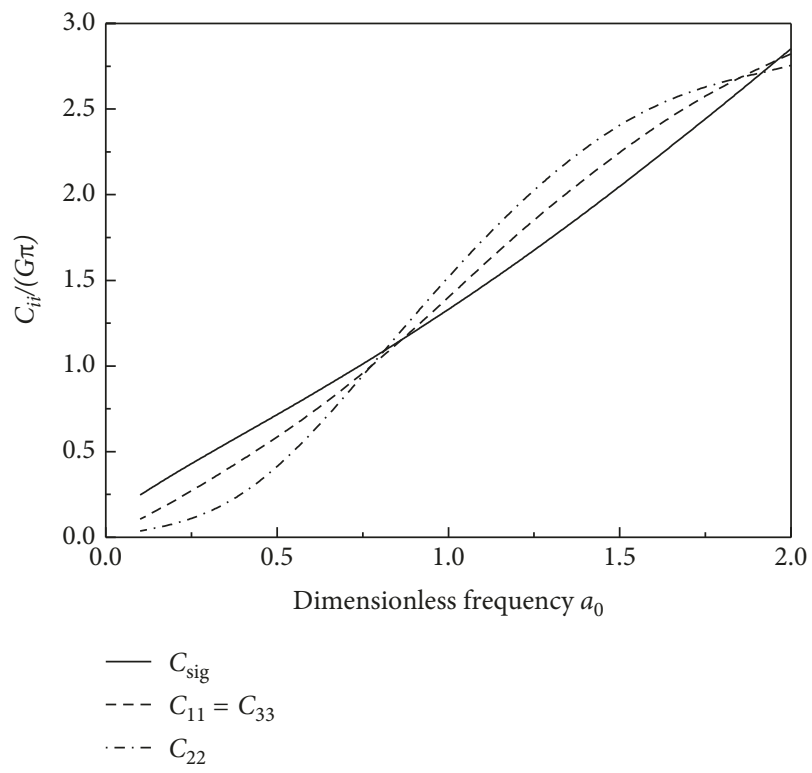

(b)

Figure 12: Vertical impedances of $K_{i i}$ and $C_{i i}$ in the impedance matrix. (a) Real part. (b) Imaginary part.

$C_{i i}(i=1,2$, and 3$)$ are shown in Figure 12, and the corresponding coupling impedances $K_{i j}$ and $C_{i j}$ of paired footings are shown in Figure 13. The impedance of an isolated footing $K_{\text {sig }}$ and $C_{\text {sig }}$ without the SSSI effect is also presented in Figures 12 and 13 for comparisons. It can be seen from Figure 12 that the vertical impedances of $K_{i i}$ and $C_{i i}$ influenced by the SSSI effect fluctuate around that of the isolated one. It can be seen from Figure 13(a) that the coupling stiffness $K_{21}$ and $K_{23}$ are negative for low frequencies. Therefore, although the stiffness of $K_{22}$ is higher than the stiffness of a single footing $K_{\text {sig }}$ in Figure 12(a) for low frequencies, the stiffness of the central footing $\sum_{j=1}^{3} K_{2 j}$ is still lower than $K_{\text {sig }}$ when the footing group has the same displacement. It agrees with the general behavior of group footings and agrees with the results of Figures 7 and 8 . Moreover, the comparison between $K_{11}$ and $K_{22}$ in 


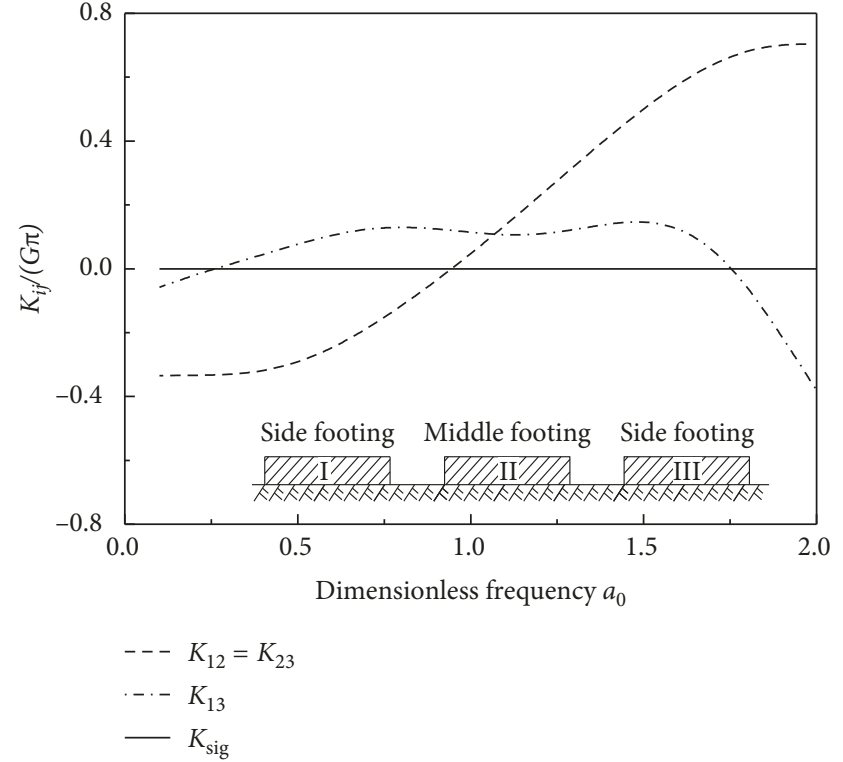

(a)

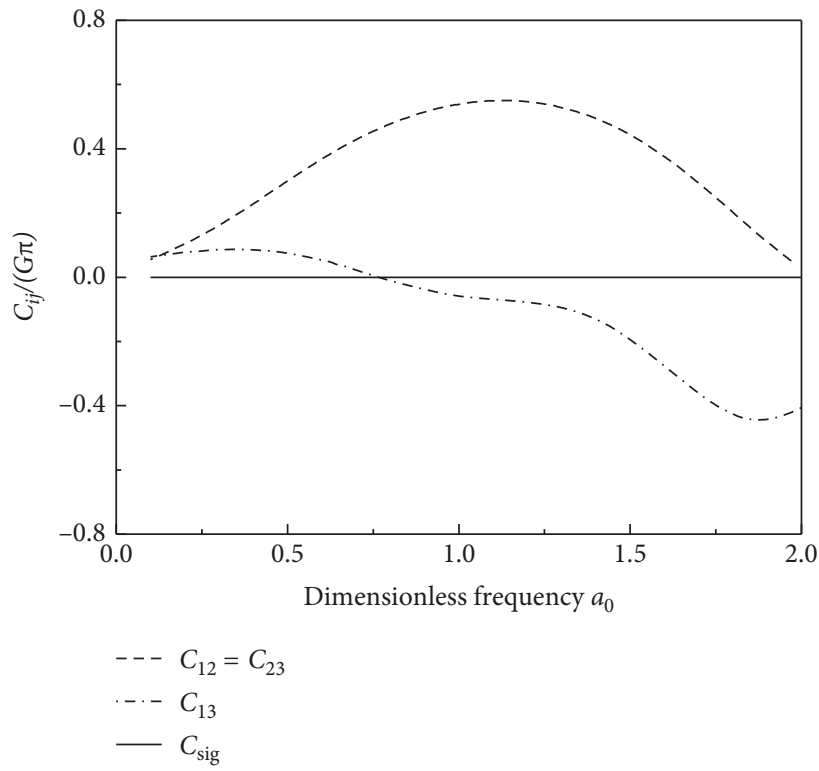

(b)

FIgURE 13: Vertical coupling impedance of $K_{i j}$ and $C_{i j}$ in the impedance matrix. (a) Real part. (b) Imaginary part.

Figure 12, as well as $C_{11}$ and $C_{22}$, indicates that the middle footing experiences a greater SSSI effect than the side ones. The coupling impedances of paired footings given in Figure 13 show that the SSSI effect between the middle footing and its adjacent ones is significantly greater than that between two side footings due to a smaller distance ratio.

\section{Conclusions}

An efficient semianalytical method has been presented for modelling the vertical dynamic interaction among a group of strip footings rested on the elastic half-space. The approach is of significance for dynamic analysis and seismic design of strip footings with close space, such as a series of parallel tracks or building foundations with a high ratio of length to width. The dynamic contact pressures and impedance matrix of a group of rigid strip footings considering the SSSI effect have been studied in detail, and the following conclusions can be emphasized:

(1) The present method overcomes the mathematical limitations in the mixed boundary-value method and can provide the dynamic impedances of multiple footings within a wide scope of excitation frequency. The computational stability and accuracy of the present method have been verified by the convergence studies and the comparison examples.

(2) The distributions of contact pressures for strip footing groups are influenced by the frequency of excitation and the SSSI effect. Therefore, those symmetric distribution assumptions for a single footing would cause a considerable error in SSSI analysis.

(3) The SSSI effect increases with the decrease of distance ratio $S / L$ between paired strip footings. It is advisable to consider the SSSI effect among footing groups when $S / L$ reaches a small ratio less than 4.0 , especially for the case of a low exciting frequency $a_{0}$ from 0.5 to 1.5 . Poisson's ratio of the half-space has little effect on this critical value of $S / L$.

(4) The dynamic impedance of a strip footing in group fluctuates around that of a single one. For strip footings located in the different positions of the group, the middle footing generally suffers a greater SSSI effect than the side ones.

(5) Although the results in this paper are limited to the homogeneous half-space, the presented discretized method can be extended to the layered half-space with the fundamental solution of the wave equation of layered half-space, which will be derived in our further research by a transferred matrix method.

\section{Data Availability}

No data were used to support this study.

\section{Conflicts of Interest}

The authors declare that there are no conflicts of interest regarding the publication of this paper.

\section{Acknowledgments}

The financial supports from the National Natural Science Foundation of China (51708179), Natural Science Foundation of Jiangsu Province (BK20170299), China Postdoctoral Science Foundation (2018M632216), and Fundamental Research Funds for the Central Universities (2016B15014) are greatly acknowledged. 


\section{References}

[1] J. P. Wolf, Dynamic Soil-Structure Interaction, Prentice-Hall, Englewood Cliffs, NJ, USA, 1985.

[2] S. C. Dutta and R. Roy, "A critical review on idealization and modeling for interaction among soil-foundation-structure system," Computers and Structures, vol. 80, no. 20, pp. 1579-1594, 2002.

[3] J. M. Roesset, "Soil structure interaction the early stages," Journal of Engineering and Applied Sciences, vol. 16, no. 1, pp. 1-8, 2013.

[4] E. S. Reissner, "Axialsymmetrische durch eine sehuttelnde masse erregte sehwingungen-eines homogenen elastisehen halbraumes," Ingenieur-Archiv, vol. 7, no. 6, pp. 381-396, 1936.

[5] T. Y. Sung, "Vibration in semi-infinite solids due to periodic surface loadings," Symposium on Dynamic Testing of Soils, vol. 156, no. 1, pp. 35-64, 1953.

[6] G. N. Bycroft, "Forced vibrations of a rigid circular plate on a semi-infinite elastic space and on an elastic stratum," Philosophical Transactions of the Royal Society A, vol. 248, no. 948, pp. 327-368, 1956.

[7] I. Anam and J. M. Roesset, "Dynamic stiffnesses of surface foundations: an explicit solution," International Journal of Geomechanics, vol. 4, no. 3, pp. 216-223, 2004.

[8] J. E. Luco and R. A. Westmann, "Dynamic response of a rigid footing bonded to an elastic half-space," Journal of Applied Mechanics, vol. 39, no. 2, pp. 527-534, 1972.

[9] X. H. Ma, Y. M. Cheng, and S. K. Au, "Rocking vibration of a rigid strip footing on saturated soil," Computers and Geotechnics, vol. 36, no. 6, pp. 928-933, 2009.

[10] T. Jiang and X. X. Song, "Analysis of impedance functions of strip foundations embedded in stratified soils by using thin layer method," Chinese Quarterly of Mechanics, vol. 30, no. 1, pp. 62-70, 2009.

[11] E. Kausel and J. M. Roesset, "Semianalytic hyperelement for layered strata," Journal of Engineering Mechanical Division, vol. 103, no. 4, pp. 569-588, 1977.

[12] G. Lin, Z. J. Han, H. Zhong, and J. B. Li, "A precise integration approach for dynamic impedance of rigid strip footing on arbitrary anisotropic layered half-space," Soil Dynamics and Earthquake Engineering, vol. 49, no. 3, pp. 96-108, 2013.

[13] W. X. Zhong, J. H. Lin, and Q. Gao, "The precise computation for wave propagation in stratified material," Int. J. Numer. Meth. Eng. vol. 60, no. 1, pp. 11-25, 2004.

[14] Y. Wang, R. K. N. D Rajapakse, and A. H. Shah, "Dynamic interaction between flexible strip foundations," Earthquake Engineering and Structural Dynamics, vol. 20, no. 5, pp. 441-454, 1991.

[15] M. L. Lou, H. F. Wang, X. Chen, and Y. Zhai, "Structuresoil-structure interaction: literature review," Soil Dynamics and Earthquake Engineering, vol. 31, no. 12, pp. 1724-1731, 2011.

[16] R. A. Parmelee, "Building-foundation interaction effects," Journal of Engineering Mechanical Division, vol. 93, pp. 131$152,1967$.

[17] G. B. Warburton, J. D. Richardson, and J. J. Webster, "Forced vibrations of two masses on an elastic half space," Journal of Applied Mechanics, vol. 38, no. 1, pp. 148-156, 1971.

[18] G. S. Liou, "Dynamic stiffness matrices for two circular foundations," Earthquake Engineering and Structural Dynamics, vol. 23, no. 2, pp. 193-210, 1994.

[19] R. Betti, "Effects of the dynamic cross-interaction in the seismic analysis of multiple embedded foundations,"
Earthquake Engineering and Structural Dynamics, vol. 26, no. 10, pp. 1005-1019, 1997.

[20] T. Chrysoula and W. Armand, "Simulation of seismic response in an idealized city," Soil Dynamics and Earthquake Engineering, vol. 23, no. 5, pp. 391-402, 2003.

[21] L. A. Padron, J. J. Aznarez, and O. Maeso, "Dynamic structure-soil-structure interaction between nearby piled buildings under seismic excitation by BEM-FEM model," Soil Dynamics and Earthquake Engineering, vol. 29, no. 6, pp. 1084-1096, 2009.

[22] P. Ghosh, "FLAC based numerical studies on dynamic interference of two nearby embedded machine foundations," Geotechnical and Geological Engineering, vol. 30, no. 5, pp. 1161-1181, 2012. 


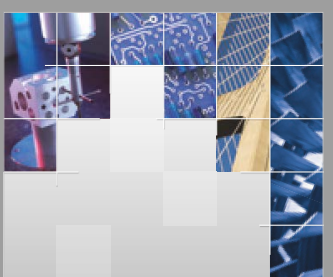

\section{Enfincering}
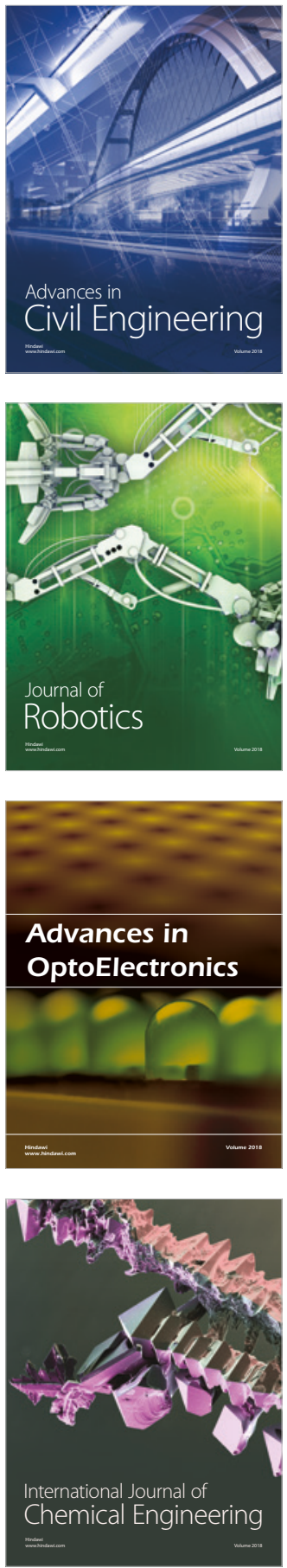

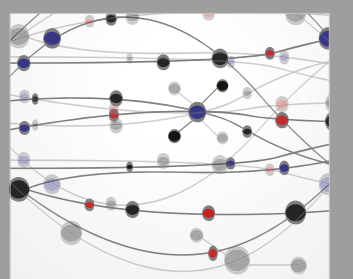

\section{Rotating \\ Machinery}

The Scientific World Journal

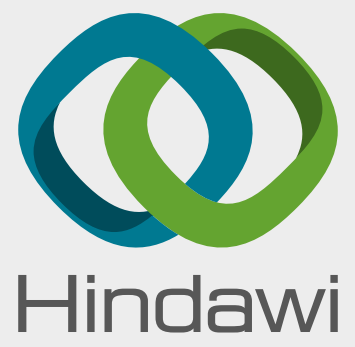

Submit your manuscripts at

www.hindawi.com
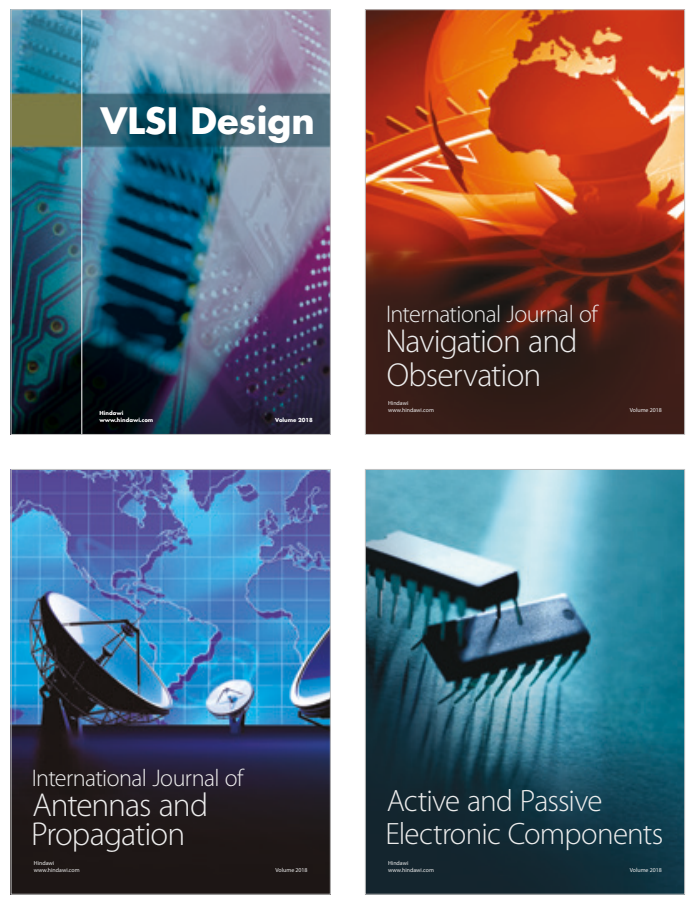
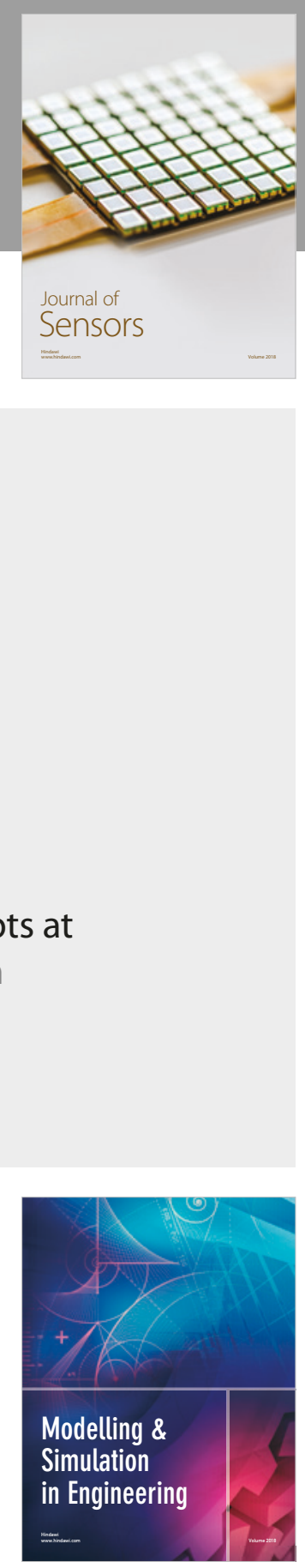

\section{Advances \\ Multimedia}
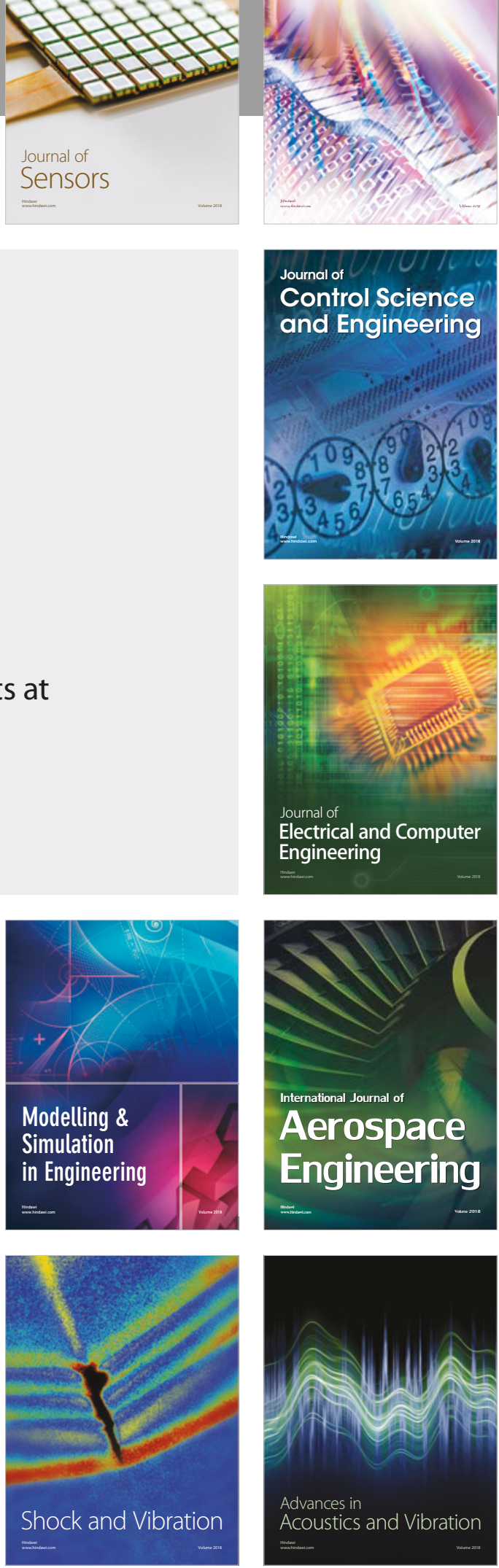